\title{
EVALUASI KONTAMINASI TRIBUTYLTIN PADA SEDIMEN DI PERAIRAN BITUNG SULAWESI UTARA
}

\author{
(Evaluation Of Tributyltin Contamination in Sediments from \\ Coastal Water of Bitung in North Sulawesi)

\section{Suzanne Lydia Undap}

Staf pengajar pada Jurusan Manajemen Sumberdaya Perairan FPIK UNSRAT Manado e-mail: suzanne.undap@gmail.com

Tributyltin (TBT) is an organotin, and these compounds have been widely used as an antifouling agent in marine environments since the early 1960s. Because of the extreme toxicity of TBT to non-target aquatic organisms, its use has been regulated in some countries. The International Maritime Organization (IMO) imposed a worldwide ban on TBT-based antifouling paints in 2003. However, there is no regulation established in Indonesia yet. TBT is being used in paint to antifouling in ships and contamination of TBT around shipyard is suspected in Indonesia. The aim of this study is to evaluations the current condition of the contamination of TBT in marine sediment in Manado of Indonesia, compared with those before 2015. Sediment samples ( $<5 \mathrm{~cm}$ from surface) were collected from 3 stations in the Bitung port area, by using an Eckman grab sampler in 2015 . The samples were subsequently transferred to polyethylene tube (size: $50 \mathrm{ml}$ ) and stored at $-30{ }^{\circ} \mathrm{C}$. The concentrations of TBT and its metabolite DBT (Dibutyltin) in the samples were analyzed by gas chromatography coupled to mass spectrometry (GC-MS). The result showed that the concentration of TBT and DBT were detected in the sediments of three sampling points at levels ranging from $0.20 \mathrm{mg} / \mathrm{kg} \mathrm{dw}$ to 6.67 $\mathrm{mg} / \mathrm{kg} \mathrm{dw}$. The highest concentration of TBT was found in sediments collected at Bitung Port $(6.67 \mathrm{mg} / \mathrm{kg} \mathrm{dw})$, which was close to a shipyard area. These results suggest that TBT contamination still occurred in the costal water of Bitung.

Keywords: Evaluation, Contamination, Sediment, Tributyltin, Shipyard

Tributiltin (TBT) merupakan suatu senyawa organotin, dan senyawa ini telah banyak digunakan sebagai agen antifouling di lingkungan laut sejak awal 1960-an. Karena sifat racun yang tinggi dari TBT untuk organisme air non-target, penggunaannya telah diatur di beberapa negara. Organisasi Maritim Internasional (IMO) memberlakukan larangan seluruh dunia pada cat antifouling berbasis TBT pada tahun 2003. Namun, di Indonesia belum ada peraturan yang diberlakukan untuk penggunaan TBT. TBT sedang digunakan dalam cat untuk antifouling di kapal dan kontaminasi TBT sekitar galangan kapal diduga di Indonesia. Tujuan dari penelitian ini adalah untuk mengevaluasi kondisi saat ini kontaminasi TBT di sedimen laut di Manado,Indonesia, dibandingkan dengan hasil penelitian sebelum tahun 2015. Sampel sedimen ( $<5 \mathrm{~cm}$ dari permukaan) dikumpulkan dari 3 titik sampel di daerah pelabuhan Bitung, dengan menggunakan grab sampler Eckman pada tahun 2015. Sampel kemudian dipindahkan ke tabung polietilen (ukuran: $50 \mathrm{ml}$ ) dan disimpan di $-30^{\circ} \mathrm{C}$. Konsentrasi TBT dan metabolitnya yaitu DBT (Dibutyltin) dalam sampel dianalisis dengan kromatografi gas ditambah dengan spektrometri massa (GC-MS). Hasil penelitian menunjukkan bahwa konsentrasi TBT dan DBT terdeteksi dalam sedimen dari tiga titik sampling pada tingkat mulai dari $0,20 \mathrm{mg} / \mathrm{kg}$ dw ke 6.67 $\mathrm{mg} / \mathrm{kg} \mathrm{dw}$. Konsentrasi tertinggi TBT ditemukan dalam sedimen yang dikumpulkan di Pelabuhan Bitung $(6,67 \mathrm{mg} / \mathrm{kg} \mathrm{dw})$, yang dekat dengan daerah galangan kapal. Hasil ini menunjukkan bahwa kontaminasi TBT masih terjadi di perairan pesisir Bitung.

Kata kunci: Evaluasi, Kontaminasi, Sedimen, Tributyltin, Galangan kapal. 


\section{PENDAHULUAN}

Misi pemerintah di bidang perikanan dan kelautan yaitu: menyejahterakan masyarakat Kelautan dan Perikanan. Salah satu upaya mencapai misi ini yakni perikanan dan ilmu kelautan, program yang mengacu pada bidang unggulan dalam perguruan tinggi lewat riset unggulan universitas (RUU). Bidang unggulan ini diharapkan juga dapat membantu untuk tercapainya visi: Indonesia Penghasil Produk Kelautan dan Perikanan Terbesar Tahun 2025 (KKP RI, 2014).

Namun seiring dengan program unggulan ini, masalah pencemaran lingkungan laut menjadi masalah global saat ini. Salah satu masalah global saat ini adalah kontaminasi polutan TBT. TBT telah banyak digunakan sebagai agen antifouling di lingkungan laut sejak awal 1960-an (Hugget et al., 1992), dan diterapkan ke lambung kapal dan peralatan budidaya laut . Karena daya toksisitas TBT yang tinggi pada organisme perairan (Clark et al., 1988), penggunaan TBT telah diatur di seluruh dunia sejak tahun 1980-an. Organisasi Maritim Internasional (IMO) memberlakukan pembatasan penggunaan TBT di seluruh dunia pada tahun 2003 (Champ, 2000).

Meskipun ada pembatasan oleh IMO untuk penggunaan TBT tapi TBT masih terdeteksi di wilayah pesisir di seluruh dunia (Antizar-Ladislao, 2008). TBT terdeteksi pada sedimen dan ikan yang dikumpulkan dari wilayah pesisir Indonesia (Sudaryanto et al., 2005; Rumengan et al., 2008 dan Undap et al., 2013a). Penyelidikan Undap et al. (2013b) pada tahun 2010-2012 polutan TBT terdeteksi di Wharf roach (Ligia exotica Roux) yang dikumpulkan dari pelabuhan Bitung, Indonesia, di mana konsentrasi TBT yang tinggi terdeteksi dalam sedimen (Undap et al., 2013a). Hasil ini menunjukkan kontaminasi TBT juga terjadi pada organisme pesisir di Indonesia.
Efek kontaminasi TBT pada ekosistem laut tropis, misalnya, di Indonesia, membutuhkan perhatian. Daerah ini menjadi daerah kritis, dan harus mulai dibenahi untuk kriteria penilaian risiko dan pemantauan dasar untuk melindungi ekosistem laut tropis di tengah meningkatnya gangguan antropogenik (Peters et al., 1997).

Pada penelitian ini dilakukan evaluasi potensi area yang menjadi sumber kontaminasi TBT yang tinggi dengan sampel sedimen, sehingga dapat terdeteksi kontaminasi TBT pada perairan sekitarnya. Selanjutnya, diharapkan akan menjadi bahan saran kebijakan adanya regulasi penggunaan TBT di Indonesia khususnya di Provinsi Sulawesi Utara.

\section{METODE PENELITIAN}

\section{Tempat dan Waktu Penelitian}

Penelitian ini dilakukan di Perairan Pelabuhan Bitung Provinsi Sulawesi Utara. Waktu pengambilan sampel dalam penelitian mulai dilakukan pada akhir bulan Juli 2015 sampai September 2015.

\section{Pengambilan Sedimen Sampel}

Pemilihan lokasi pengambilan sedimen sampel dilakukan dengan mengamati kondisi lingkungan perairan, kesesuain areal yang diduga tercemar. Pengambilan sampel sedimen dilakukan pada 3 titik sampling (Gambar 1).__Pengamatan kondisi lingkungan perairan untuk penentuan lokasi sampling dilakukan secara hatihati agar supaya tidak menimbulkan konflik dengan perusahan dok kapal, dimana perairan Bitung sekitar pelabuhan terdapat beberapa perusahan dok kapal yang dicurigai sebagai sumber pencemaran. Sampel sedimen (dalam $5 \mathrm{~cm}$ ) dikumpulkan dengan menggunakan grab sampler Eckman (Rickly perusahaan hidrologi, AS). Sampel kemudian dipindahkan ke 


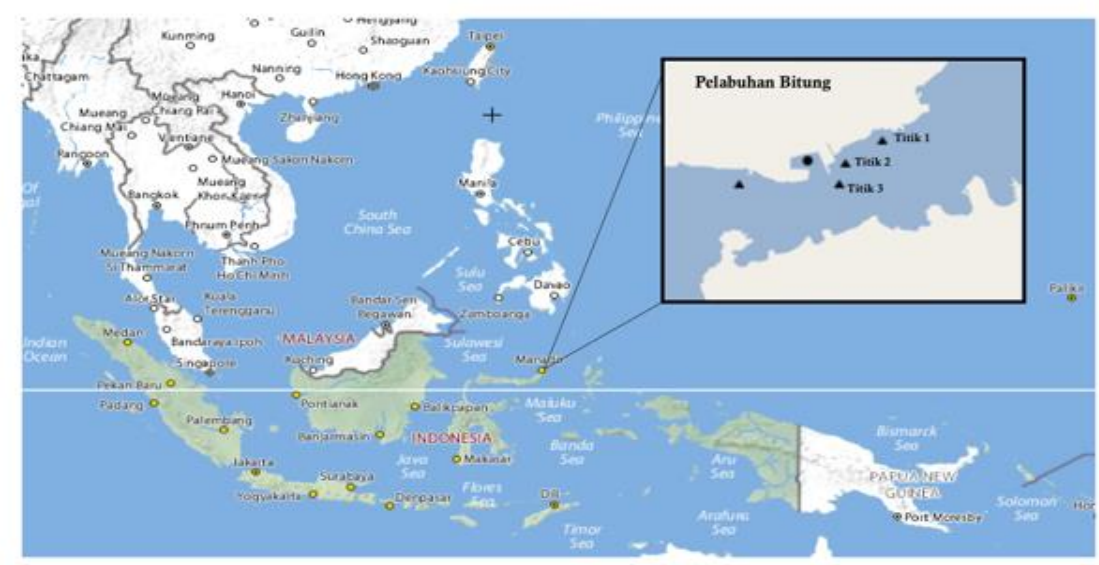

Gambar 1. Lokasi pengambilan sampel sedimen

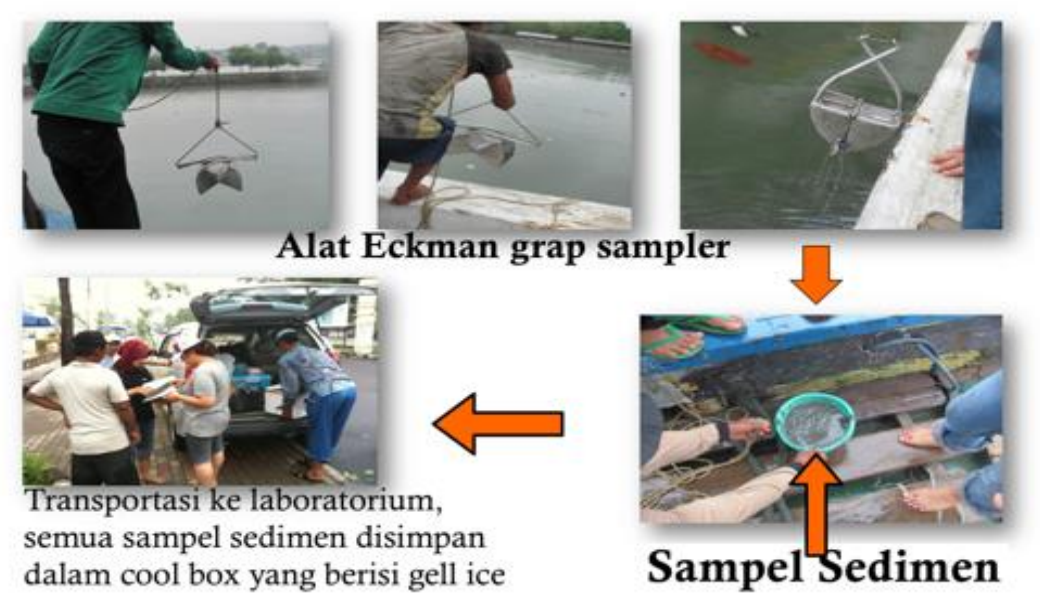

Gambar 2. Sampling sedimen sampel

tabung $50 \mathrm{~mL}$ polietilen dan selama transportasi disimpan dalam cool box (Gambar 2). Selanjutnya sampel disimpan beku pada suhu $-20^{\circ} \mathrm{C}$ sampai dilakukan analisis TBT.

\section{Prosedur Analisis TBT untuk Sampel Sedimen}

Konsentrasi senyawa butyltin dalam sampel sedimen dianalisis mengikuti metode yang diterbitkan oleh Undap et al., (2013) dengan sedikit modifikasi. Seperti yang disajikan pada Gambar 3. Untuk analisis TBT dilakukan di Laboratorium Marine Environmental Science Universitas Kyushu Jepang.

\section{HASIL DAN PEMBAHASAN}

Tributyltin (TBT) terdeteksi dalam sampel sedimen di semua 3 titik pengambilan sampel di Pelabuhan Bitung dengan konsentrasi TBT dari 


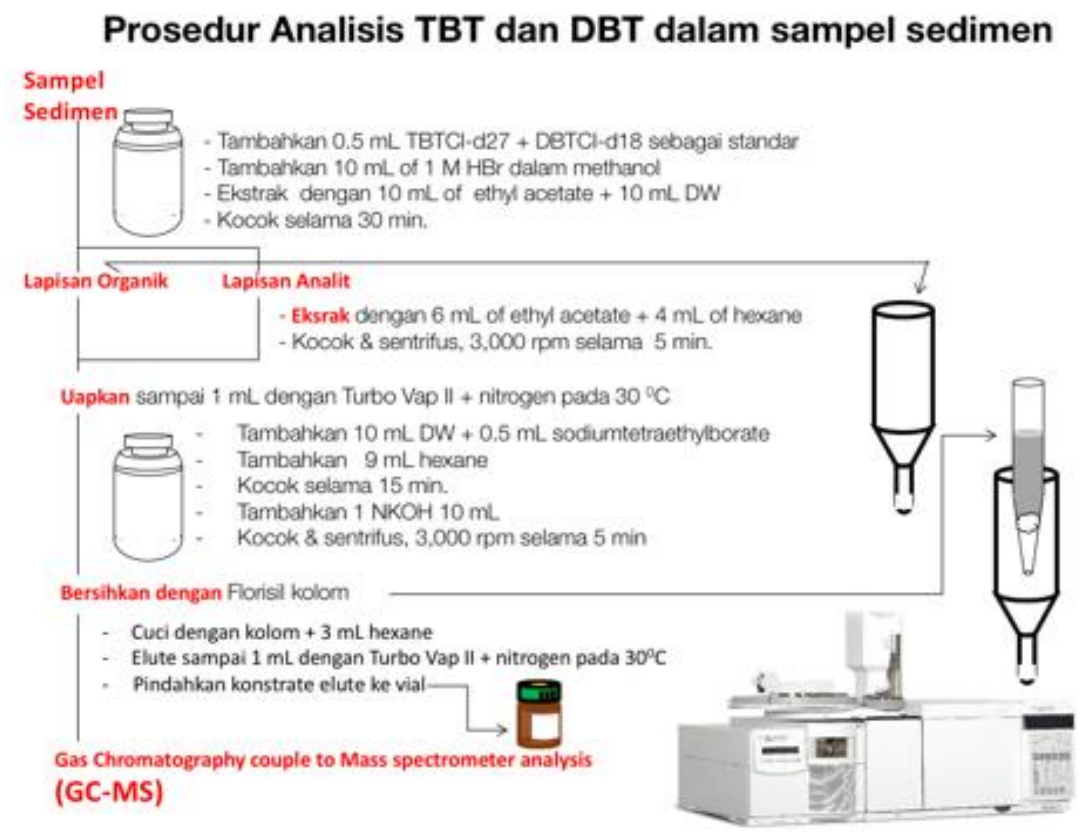

Gambar 3. Prosedur analisis TBT dan DBT pada sedimen sampel.

0,2-6,67 $\mathrm{mg} / \mathrm{kg}$ berat kering (bk). Konsentrasi TBT tertinggi yaitu 6,67 $\mathrm{mg} / \mathrm{kg}$ bk (Titik 2) ditemukan pada sampel yang diambil dari lokasi di muka galangan kapal di pelabuhan Bitung dan konsentrasi tertinggi berikutnya ditemukan dalam sampel dekat galangan kapal di pelabuhan Bitung (Titik 1; 2,15 mg/kg bk). Konsentrasi TBT rendah (Titik 3; 0,20 $\mathrm{mg} / \mathrm{kg}$ bk) terdeteksi dalam sampel dari lokasi pengambilan sampel jauh dari galangan kapal (Gambar 1).

Sudaryanto et al. (2005) dan Rumengan et al. (2008) melaporkan bahwa konsentrasi total butyltin (TBT, DBT dan monobutyltin) dalam sedimen di Indonesia berkisar antara 0,51-320 $\mathrm{ng} / \mathrm{g}$ dw pada tahun 1998. Selanjutnya Undap et al. (2013a) mendeteksi konsentrasi TBT dalam sedimen di pelabuhan Bitung adalah $4,25 \mu \mathrm{g} / \mathrm{g}$ bb. Pada pengambilan sampel tahun 2015 dalam penelitian ini ditemukan konsentrasi TBT $(6,67 \mathrm{mg} / \mathrm{kg} \quad \mathrm{bk})$. Penelitian ini sebagai data primer adalah lebih tinggi dari pada yang dilaporkan peneliti terdahulu seperti yang di atas sebagai data sekunder kami. Data primer kami menunjukkan bahwa kontaminasi TBT masih terjadi di Indonesia bahkan cenderung meningkat. Perlu dicatat bahwa sedimen dari galangan kapal di pelabuhan secara periodik dibuang ke laut, yang dapat mengakibatkan kontaminasi luas di daerah pesisir Indonesia. Senyawa Butyltin telah diidentifikasi sebagai kontaminan yang menimbulkan kekhawatiran di sedimen laut (Rumengan et al., 2008).

Penggunaan TBT belum diatur di Indonesia, meskipun pencemaran lingkungan Indonesia dengan senyawa butyltin telah dilaporkan (Sudaryanto et al., 2005; Midorikawa et al., 2004; Undap et al., 2013a). Total konsentrasi butyltin di sedimen, bivalvia, dan ikan adalah tercatat $0,023-0,32 \mathrm{mg} / \mathrm{g}$, 0,005-0,064 mg/g, 0,00041-0,019 ug/g dan 0,209-0,425 mg/g telah ditemukan di pelabuhan laut kota Jakarta, Surabaya, Medan dan Bitung Manado (Rumengan et al., 2008; Harino et al., 2012). 
Dalam penelitian ini, kami menemukan konsentrasi TBT yang sangat tinggi di sedimen yang dikumpulkan dari pelabuhan Bitung Indonesia, di mana sampai saat ini belum ada peraturan untuk penggunaan TBT. Hasil ini menegaskan bahwa, dengan tidak ada pembatasan penggunaan TBT saat ini, akan mengakibatkan adanya risiko tinggi kontaminasi TBT di laut Indonesia khususnya Manado.

\section{KESIMPULAN DAN SARAN}

\section{Kesimpulan}

Terevaluasi pada penelitian ini kontaminasi TBT yang sangat tinggi di sedimen yang dikumpulkan di depan galangan kapal dalam pelabuhan Bitung yang berada di Manado. Sehingga, kegiatan galangan kapal merupakan sumber utama pencemaran TBT di Manado-Indonesia, di mana sampai saat ini belum ada peraturan untuk penggunaan TBT. Hasil ini menegaskan bahwa, dengan tidak ada pembatasan penggunaan TBT saat ini, akan mengakibatkan adanya risiko tinggi kontaminasi TBT di laut Indonesia khususnya di Manado.

\section{Saran}

Dari hasil penelitian ini kami
menyarankan bahwa sangat
dibutuhkan evaluasi lebih lanjut untuk
mengetahui kontaminasi TBT di
organisme perairan seperti ikan.

\section{DAFTAR PUSTAKA}

Antizar-Ladislao, B. 2008. Environmental levels, toxicity and human exposure to tributyltin (TBT)-contaminated marine environment: a review. Environ. Int. 34:292-308.

Arai, T., Harino, H. 2009. Contamination by Organotin Compounds in Asia. In "Ecotoxicology of Antifouling
Biocides". T. Arai, Harino, H., Ohji, M., Langston, W.J. (Eds). Springer Japan, Tokyo. p 61-74.

Bao, V.W.W., Leung K.M.Y., Qiu, J-W., Lam, M.H.W. 2011. Acute toxicities of five commonly used antifouling booster biocides to selected subtropical and cosmopolitan marine species. Mar. Pollut. Bull. 62:1147-1151.

Champ, M.A. 2000. A review of organotin regulatory strategies, pending actions, related costs and benefits. J. Sci. Total Environ. 258:21-71.

Clark, E.A., Sterrit, R.M., Lester, J.N. 1988. The fate of tributyltin in the aquatic environment. $J$. Environ. Sci. Technol. 22:600604.

Ellis, D.V., Pattisina, L.A. 1990. Widespread neogastropod imposex: A biological indicator of global TBT contamination? Mar. Pollut. Bull. 21:248-253.

Evans, S.M., Dawson, M., Day, J., Frid, C.L.J., Gill, M,E., Pattisina, A., Porter, J. 1995. Domestic Waste and TBT Pollution in Coastal areas of Ambon Island (Eastern Indonesia). Mar. Pollut. Bull. 30:109-115.

Gallaher, A.A., Hall, E.R., Bonzongo, J.R., Delfino, J.J. 2006. Compilation and synthesis of existing persistent organic pollutants (POPs) and heavy metals data for Gulf Coast network national parks: a report to the National Park Service. University of Florida. p 159.

Gomez-Ariza, J.L., Morales, E., Giraldez, I. 1999. Uptake and elimination of tributyltin in clams, Venerupis decussata. Mar. Environ. Res. 47:399-413. 
Harino, H., Eguchi, S., Yamamoto, Y., Kurokawa, Y., Kawai, S., Arai, T., Ohji, M., Yamato, S., Kobayashi, N., Miyazaki, N. 2008a. Distribution of organotin compounds in representative coastal areas from Japan: a review. J. Coast. Mar. Scien. 32(1):88-95.

Harino, H., Arai, T., Ohji, M., Ismail, A.B., Miyazaki, N. 2008b. Organotin contamination in Malaysia. J. Coast. Mar. Scien. 3(1):96-101.

KKP RI. 2014. Visi, Misi, Tujuan, dan Sasaran Strategis. http://kkp.go.id/index.php/visimisi-tujuan-dan-sasaranstrategis. (diunduh 7 Januari 2015).

Lilley, T.M., Ruokolainen, L., Pikkarainen, A., Laine, V.N., Kilpimaa, J., Rantala, M.J., Nikinmaa, M. 2012a. Impact of Tributyltin on Immune Response and life history traits of Chironomus riparius: single and multigeneration effects and recovery from pollution. Environ. Sci. Techno. 46:7382-7389.

Lilley, T.M., Meierjohann, A., Ruokolainen, L., Peltonen, J., Vesterinen, E., Kronberg, L., Nikinmaa, M. 2012b. Reed beds may facilitate transfer of tributyltin from aquatic to terrestrial ecosystems thought insect vector in the Archipelago Sea, SW Finland. Environ. Toxicol. Chem. 31(8), 1781-1787.

Lunn, E.M., Moreau, M A. 2004. Unmonitored trade in marine ornamental fishes: the case of Indonesia's Banggai cardinalfish (Pterapogon kauderni). Coral Reefs.
Midorikawa, S.T., Arai, T., Harino, H., Ohji, M., Cu, N.D., Miyazaki, N. 2004. Concentration of organotin compounds in sediment and clams collected from coastal areas in Vietnam. J. Environ. Pollut. 131:401-408.

Miki, S., Ikeda K., Oba Y., Satone, H., Honda, M., Shimasaki, Y., Onikura, N., Arakawa, O., Oshima, Y. 2011. Tributyltin in blood of marine fish collected from a coastal area of northern Kyushu, Japan. Mar. Pollut. Bull. 62, 2533-2536.

Navio, J.A., Marchena, F.J., Cerrillos, C., 1993. UV photolytic degradation of butyltin chlorides in water. J. Photochem. Photobiol. A: Chem. 71:97-102.

Peters, E.C., Gassman, N.J., Firman J.C., Richmond, R.H., Power, E.A. 1997. Ecotoxicology of tropical marine ecosystems. Environmental Toxicology and Chemistry. 16(1):12-40.

Rumengan, I.F.M., Ohji, M.M., Arai, T., Harino, H., Arifin, Z., Miyazaki, N. 2008. Contamination status of butyltin compounds in Indonesian coastal waters. J. Coast Mar Sci., 32:116-126.

Sudaryanto, A., Takahashi, S., Iwata, H., Shinsuke, T., Muchtar, M., Razak, H. 2005. Organotin residues and the role of anthropogenic tin sources in the coastal marine environment of Indonesia. J. Mar. Pollut. Bull. 50:208-236.

Undap. S.L., Nirmala. K., Miki. S., Inoue. S., Honda. M., Shimasaki. Y., Oshima, Y. 2013a. High tributyltin contamination in sediments from ports in Indonesia and northern Kyushu, 
Japan. J. Fact. Agr. Kyushu. U. 58:131-135.

Undap, S.L., Matsunaga, S., Honda M., Sekiguchi, T., Suzuki, N., Khalil, F., Qui, X., Shimasaki, Y., Ando, H., Sato-Okoshi, W., Sunobe, T., Takeda, S., Munehara, H., Oshima, Y.2013b. Accumulation of organotin in wharf roach (Ligia exotica Roux) and its ability to serve as a biomonitoring species for costal pollution. Ecotoxicology and Environmental Safety. 96:75-79. 